\title{
Field electron emission from a copper-based composite reinforced with carbon nanotubes
}

\author{
R. Kh. Khisamov ${ }^{\dagger, 1}$, K. S. Nazarov ${ }^{1}$, P. V. Trinh ${ }^{2}$, A. A. Nazarov ${ }^{1}$, \\ D. D. Phuong' 2 , R. R. Mulyukov ${ }^{1,3}$ \\ †r.khisamov@mail.ru \\ ${ }^{1}$ Institute for Metals Superplasticity Problems RAS, 39 S. Khalturin St., Ufa, 450001, Russia \\ ${ }^{2}$ Institute of Materials Science, Vietnam Academy of Science and Technology, 18 Hoang Quoc Viet St., Cau Giay Distr., \\ Hanoi, Vietnam \\ ${ }^{3}$ Bashkir State University, 32 Zaki Validi St., Ufa, 450076, Russia
}

Field electron emission from a copper based composite reinforced with carbon nanotubes (Cu- 4 wt.\% CNT) was studied. The composite samples were processed by mixing copper powders and carbon nanotubes (CNTs) in a ball mill followed by hot isostatic pressing. To obtain a more even distribution of CNTs, the samples were subjected to high pressure torsion (HPT). After etching, clusters of CNTs were observed on the surface of the sample. The field electron emission from the sample was measured by means of a vacuum diode consisting of an anode and cathode. The composite sample served as cathode. The dependence of the current on the voltage applied between the anode and sample was determined. The current values of 5 and $200 \mu \mathrm{A}$ were found at the potential differences of 2200 and $3400 \mathrm{~V}$, which correspond to the values of electric field 9 and $13.5 \mathrm{~V} / \mu \mathrm{m}$, respectively. The increase of voltage above $3400 \mathrm{~V}$ led to initiation of microdischarge between the anode and sample. Under the same conditions, no current was detected with pure $\mathrm{Cu}$ samples. It is assumed that the current measured on the anode with the sample of $\mathrm{Cu}-\mathrm{CNT}$ composite is the current of electrons emitted from the CNT clusters located on the surface of the sample and that this emission is of field nature. An analysis of the dependence of the current on the voltage for the composite samples is done in Fowler-Nordheim coordinates.

Keywords: field electron emission, carbon nanotubes (CNTs), metal-matrix composite, high pressure torsion (HPT).

\section{Introduction}

Carbon nanotubes (CNTs) are recently discovered as a type of new materials that possess unique mechanical and physical properties such as enhanced strength, thermal and electric conductivity etc. [1-3]. The high strength makes them promising reinforcements in composite materials [4]. Therefore, a significant interest has been given to the studies on CNT reinforced metal matrix nanocomposites in recent years. Different techniques have been proposed to process the composites: conventional sintering $[5,6]$, hot pressing $[7,8]$, spark plasma sintering $[9,10]$, flake powder metallurgy $[11,12]$, molecular level mixing $[13,14]$ etc.

Severe plastic deformation (SPD) is considered as a promising method of compacting metal-matrix CNT composites prepared by powder metallurgy $[15,16]$. The heavy deformation can result in not only better distribution of CNTs in the matrix and consolidation of the powder into bulk form, but also grain refinement of the matrix, which provides and additional strengthening. In our recent works [17-19], we studied $\mathrm{Al}$ and $\mathrm{Cu}-\mathrm{CNT}$ composites consolidated by SPD using high-pressure torsion (HPT) and found a significant improvement of the hardness with respect to that of pure metals.

The CNT reinforced metal matrix composites were also studied as field emitters for cold cathodes. In [20] patterned copper-multiwalled CNT composite emitters were fabricated by means of electrodeposition. Field emission current of about $10 \mu \mathrm{A} \cdot \mathrm{cm}^{-2}$ was obtained at the electric field of $2.5 \mathrm{~V} / \mu \mathrm{m}^{-1}$. Multiwalled CNT-cobalt composite was prepared by in situ spray coating in [21]. Current densities as high as $1000 \mu \mathrm{A} / \mathrm{cm}^{-2}$ were obtained for the same electric field. Composite electroplating followed by micromachining was used to fabricate nickel-matrix CNT composite field emitters in [22]. These authors observed the currents of about $6 \mathrm{~mA} / \mathrm{cm}^{-2}$ for the same fields.

In the composites processed in our works [17-19], many CNTs were found to be located on the surfaces of the consolidated samples in the forms of more-or-less continuous coatings or clusters (tangles) of CNTs. In other words, these studies showed that there was still a problem of a homogeneous distribution of CNTs in the matrix. Without such a distribution, it is not possible to fully exploit the strengthening potential of CNTs. On the other hand, one can assume that the CNTs and their tangles located on the surface of the composites can serve as emitters of electrons under the electric field, i.e. the composites can be considered as potential field emitters. Thus, the present work is aimed at a study of the field electron emission from the $\mathrm{Cu}-4 \mathrm{wt} . \% \mathrm{CNT}$ composite consolidated by means of HPT. 


\section{Materials and methods}

A Cu-matrix composite containing multiwall CNTs with the concentration of $4 \mathrm{wt} . \%$ was prepared for the studies of the field electron emission. As initial components for the processing of the composite, $\mathrm{Cu}$ powder of $99.5 \%$ purity with the size of particles about $10-15 \mu \mathrm{m}$ and multiwall CNTs with the purity of $95 \%$, diameters of $20-30 \mu \mathrm{m}$ and length of $30 \mu \mathrm{m}$ were taken. The process of fabricating CNTs were described in detail elsewhere [17-19]. The CNTs obtained were solved in ethanol in a concentration of $1 \mathrm{~g}$ to $100 \mathrm{ml}$ and treated by ultrasound for $3 \mathrm{~h}$ in order to disperse the nanotubes. Then the $\mathrm{Cu}$ powder and solution of CNTs in ethanol were mixed in a planetary ball mill for $6 \mathrm{~h}$ with the rotation velocity $300 \mathrm{rot} / \mathrm{min}$. The mixture thus obtained was dried and subjected to pre-compacting by hot isostatic pressing under the pressure of $0.1 \mathrm{GPa}$. As a result, diskshaped samples with the diameter of $10 \mathrm{~mm}$ and thickness of $1 \mathrm{~mm}$ were obtained.

For the compaction, in order to obtain high density close to the bulk density, homogeneous distribution of CNTs in the volume of the composite, and high strength, severe deformation by HPT as described in [23-25] was applied. The torsion straining was carried out on Bridgman anvils under the pressure of $5 \mathrm{GPa}$ at room temperature with the rotation speed of $2 \mathrm{rpm}$ up to 5 revolutions. As a result of HPT, disk-shaped samples with the diameter of $10 \mathrm{~mm}$ and thickness of $0.15 \mathrm{~mm}$ were obtained. To obtain a smooth and even surface, the samples were mechanically polished.

To characterize the morphology of CNT systems on the emitting surface, the samples were electrochemically polished and studied by means of a scanning electron microscope Mira 3LHM (Tescan, Czech Republic) equipped with an EDX spectrometer. The etching was carried out in the solution $20 \% \mathrm{H}_{3} \mathrm{PO}_{4}+80 \% \mathrm{H}_{2} \mathrm{O}$ at the voltage $12 \mathrm{~V}$ and current $0.65 \mathrm{~mA}$.

The field electron emission characteristics were measured by means of a vacuum diode consisting of an anode and cathode assembled together by isolators, the cold cathode being the sample of composite under study (Fig. 1). The anode had the same diameter as the cathode, i. e. $10 \mathrm{~mm}$. The distance between the sample and anode was set equal to $0.25 \pm 0.10 \mathrm{~mm}$. The measurements of the field electron emission were done in vacuum with the residual pressure of $10^{-6}$ Torr. A negative potential with respect to the anode was supplied to the sample. The anode current was measured by a digital voltmeter V7-78/1 (AKIP, Russia) in the regime of microampermeter. The errors of measurements of the current amounted less than $10 \%$.

\section{Results and discussion}

Electrochemical etching of the samples of the composite $\mathrm{Cu}-4 \mathrm{wt} . \% \mathrm{CNT}$ shows that on their surfaces clusters of different shapes are located (Fig. 2). The SEM studies have shown that these clusters consist of CNTs. Chemical analysis by means of EDX revealed the fraction of carbon of $60 \mathrm{wt} . \%$ in these clusters. The morphology of the surface had differences depending on the distance from the center of the sample.

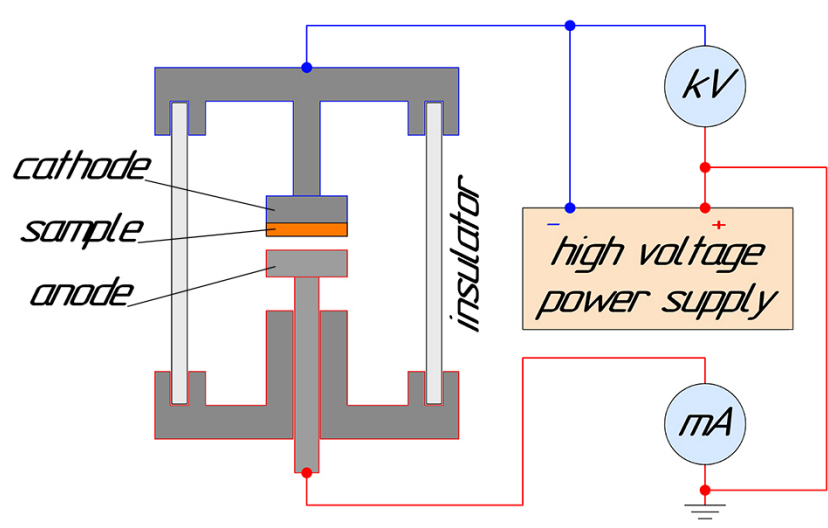

Fig. 1. (Color online) The schematic of the field electron emission.

On the surface near the center the nanotubes form more or less continuous systems of predominantly elongated shapes (Fig. 2 a,b). At a higher magnification of their images, one can observe the nanotubes forming a continuous coating (Fig. 2c). In regions of the surface located in the middle between the center and edge of the sample (Fig. $2 \mathrm{~d}, \mathrm{e}$ ), and near the edge (Fig. $2 \mathrm{~g}$, i) mainly separate clusters of CNTs having similar sizes in both directions are observed. In higher magnification images one can see that these clusters consist of a large number of CNTs linked to each other (Fig. $2 \mathrm{f}, \mathrm{i}$ ). The differences in the shapes and structures of the CNT groups are related to the nonuniform character of the strain during HPT: the local strain is maximum on the edge and minimum at the center of the sample.

In a SEM image obtained with an inclination of $20^{\circ}$ to the surface normal from a region in the middle between the center and edge of the sample (Fig. 3) one can see that the individual arrays of the CNTs protrude from the surface to different heights. These arrays have sharp tips, the radius of curvature of which, as one can estimate from the images, are less than $1 \mu \mathrm{m}$.

The dependence of the anode current, $J$, on the voltage applied between the anode and cathode, $U$, is presented in Fig. 4. The current of $J=5 \mu \mathrm{A}$ is detected under the voltage of $U=2200 \mathrm{~V}$, which corresponds to the electric field intensity $9 \mathrm{~V} / \mu \mathrm{m}$ for the distance $0.25 \mathrm{~mm}$ between the anode and cathode. With an increase of the voltage the current also increases and amounts $J=0.2 \mathrm{~mA}$ at the voltage $U=3400 \mathrm{~V}$ (the field intensity $13.5 \mathrm{~V} / \mu \mathrm{m}$ ). At the voltages above $U=3400 \mathrm{~V}$ a microdischarge between the cathode and anode was observed and the anode current was unstable. Further increase of the voltage resulted in an increase of the number of discharges. Such discharges are often observed during the investigations of the field emission from cold cathodes [26].

For a comparison to the data obtained, a sample of pure copper was also studied under the same conditions. With a cathode of this sample, no anode current under the voltage between the anode and cathode was observed.

One can assume that the current detected on the anode during the measurements with the $\mathrm{Cu}-4 \mathrm{wt}$.\% CNT composite is the current of electrons emitted by the clusters of CNTs located on the surface of the sample and the emission is of field character. 


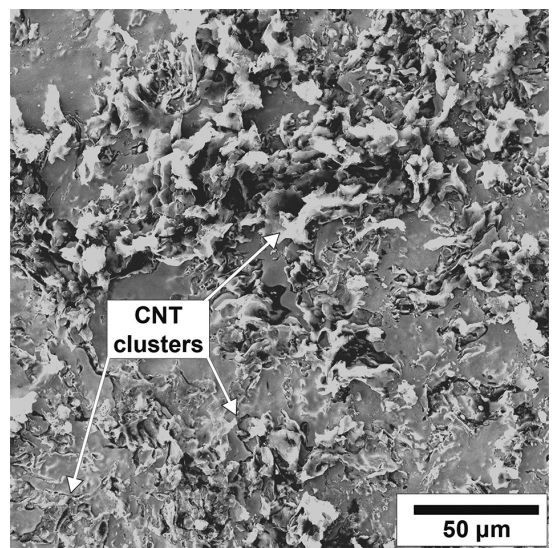

a

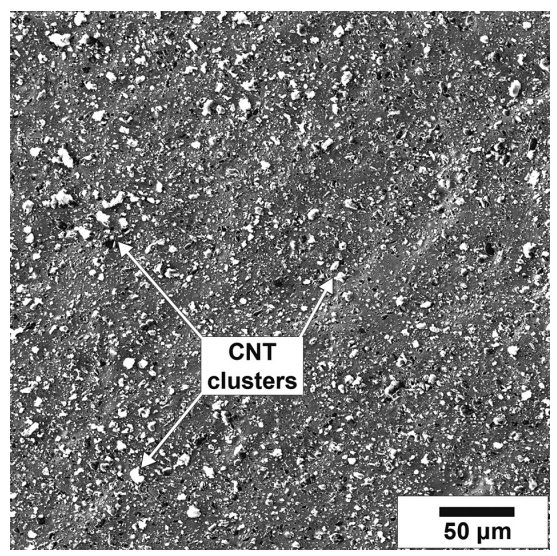

$\mathrm{d}$

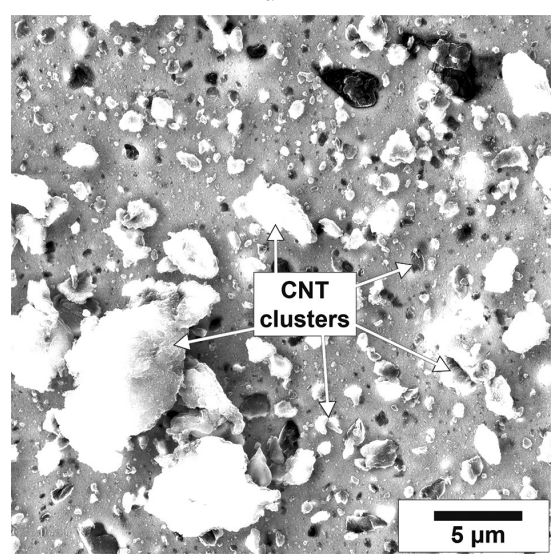

g

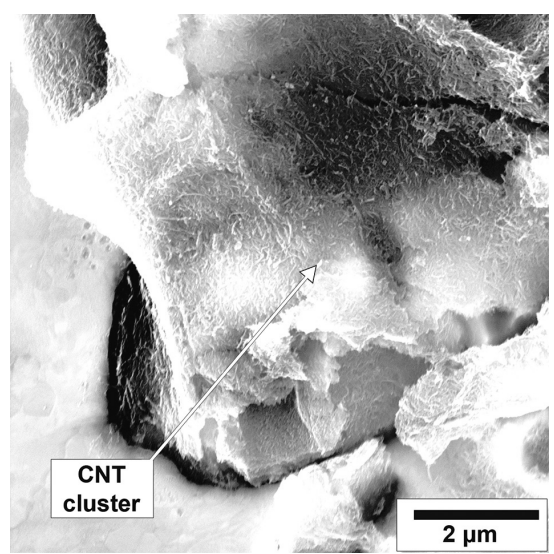

b

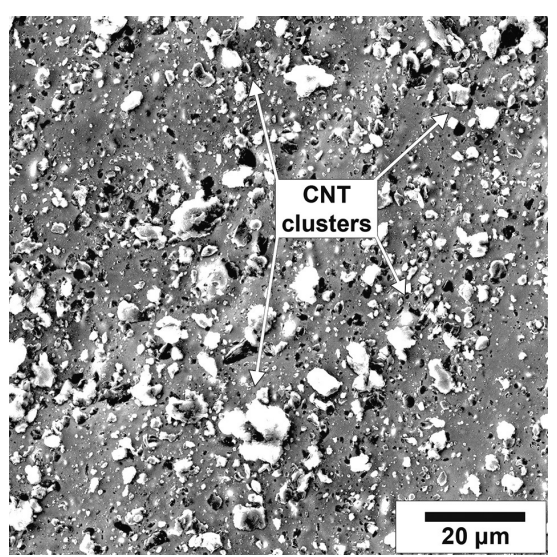

e

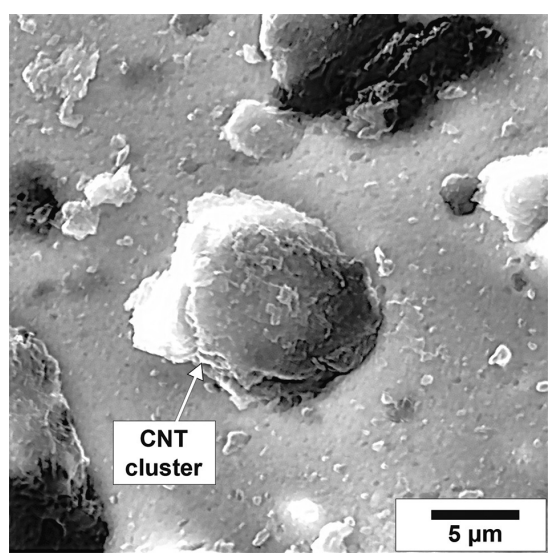

$\mathrm{h}$

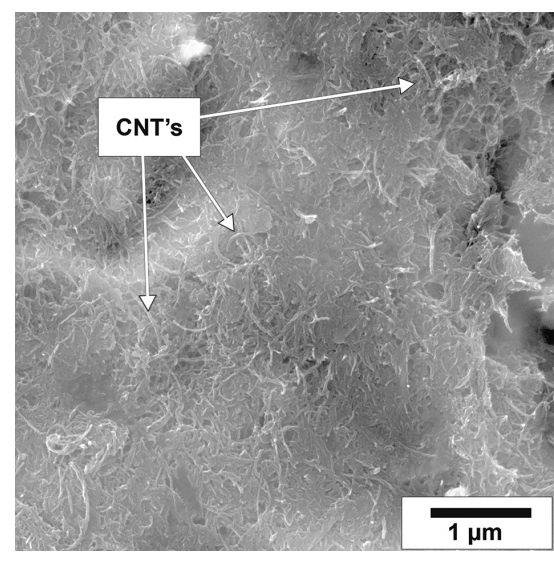

c
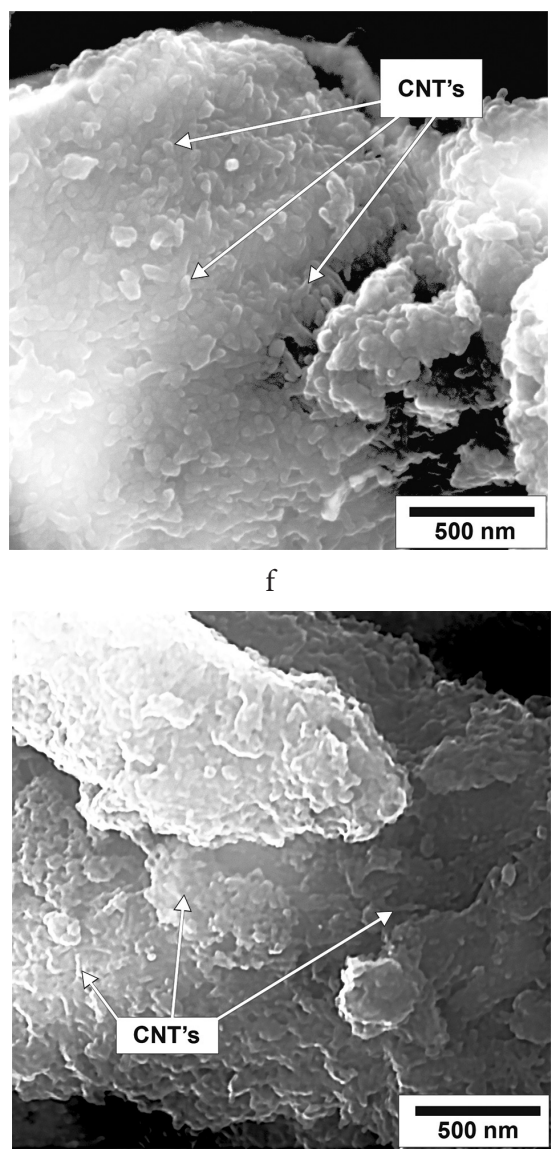

i

Fig. 2. SEM images of the surface of the Cu- 4 wt.\%CNT composite with different magnifications: near the center of the sample (a, b, c); at a middle distance between the center and the edge ( $, e, f)$; near the edge of the sample $(\mathrm{g}, \mathrm{h}, \mathrm{i})$. The surface has been electrochemically etched before observations.

The dependence of the field emission current on the potential difference is described by Fowler-Nordheim equation:

$$
J=1.54 \times 10^{-6} \frac{S \beta^{2} U^{2}}{t^{2}(y) \varphi} \exp \left[-6.83 \times 10^{7} \frac{\varphi^{3 / 2}}{\beta U} \theta(y)\right]
$$

where $J$ is the current of electrons, $U$ is the potential difference applied, $\varphi$ is the electron work function, $S$ is the emitting area, $t(y)$ is a tabulated function, $\theta(y)$ is the Nordheim function, and $\beta=2 /(r \cdot \ln (R / r))$ is the formfactor (field enhancement factor) of the cathode tip in the shape of a paraboloid of rotation, $r$ is the curvature radius of the tip, $R$ is the distance of the tip from the anode [27]. The emission current depends not only on the applied voltage and the distance between anode and cathode, but also on the tip curvature and electron work function.

The field electron emission from cold cathodes is conveniently analyzed in terms of the dependence of the current on the voltage in Fowler-Nordheim coordinates. For cold cathodes made of a single tip this dependence is linear. The linear dependence for the single tip is the proof of the mechanism of field electron emission [28]. However, during the measurements of field emission from cold cathodes, which 


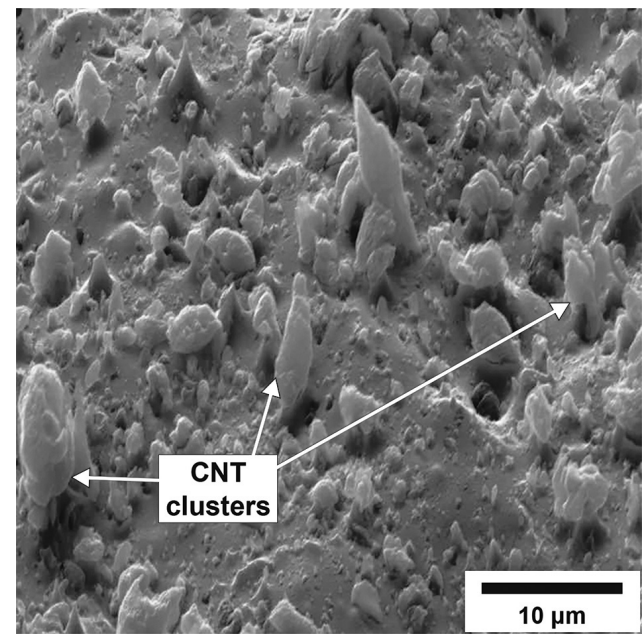

Fig. 3. SEM image of the surface of the sample of $\mathrm{Cu}-4 \mathrm{wt} . \% \mathrm{CNT}$ composite taken at an angle $20^{\circ}$ to the normal.

have many tips on the emitting surface, the dependence of the current on the voltage is non-linear [29].

The dependence of the current $J$ on the applied potential difference $U$ for the Cu- 4 wt.\%CNT composite in FowlerNordheim coordinates is nonlinear (Fig. 5). At the values of the inverse voltage $1000 / U$ from 0.45 to $0.34 \mathrm{~V}^{-1}$ the current increases linearly with the inverse voltage. This behavior can be explained with the fact that the field emission in this interval occurs from all clusters which can emit electrons and the increase of the voltage results in an increase of the current proportional to $1000 / U$. In the interval of $1000 / U$ from 0.34 to $0.3 \mathrm{~V}^{-1}$ the increase of the current slows down and the slope of the dependence decreases. This decrease can be explained assuming that at the voltage values close to $0.34 \mathrm{~V}^{-1}$ the CNT clusters give a maximum emission current and above this limit the tips of the clusters are destroyed due to resistive heating [30] which results in an increase of the curvature radius of the tips. The latter leads to a reduction of the field enhancement factor $\beta$ which, in turn, results in a decrease of the emission current from individual clusters as compared to the value which would be obtained with the linear dependence. This results in a general weakening of the dependence of emission current on the inverse voltage.

\section{Conclusions}

In this work, we fabricated a copper-matrix composite reinforced by $4 \mathrm{wt} . \%$ carbon nanotubes by mixing in a ball mill followed by hot isostatic pressing and high-pressure torsion. Electrochemical etching allowed us to reveal CNT systems on the surface of the sample in the forms of separate clusters and continuous films. Field electron emission has been studied from the sample by means of a vacuum diode method. Anode currents of 5 and $200 \mu \mathrm{A}$ were detected at the voltages of 2200 and $3400 \mathrm{~V}$, respectively. The further increase in the voltage resulted in microdischarges between the anode and the sample. No field emission current from the pure $\mathrm{Cu}$ sample was observed in the same conditions. It is assumed that the anode current in the case of composite cathode is due to the field electron emission from the clusters of CNTs located on the surface of the sample.

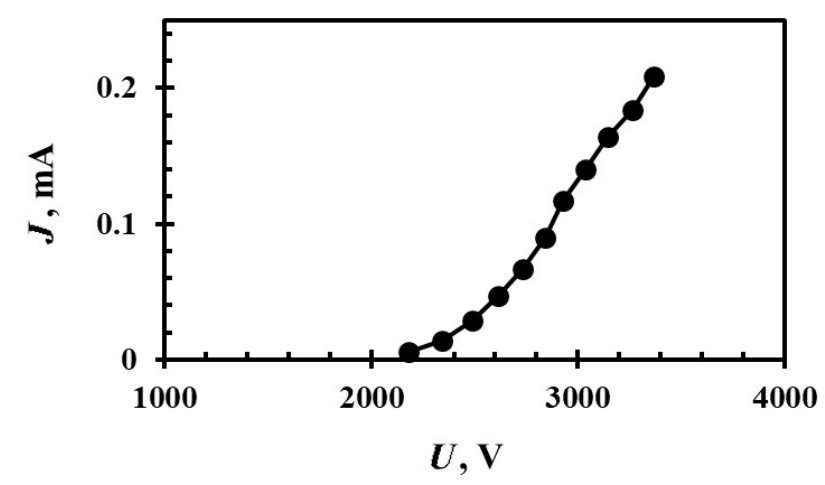

Fig. 4. Current-voltage diagram of the field electron emission from the sample of $\mathrm{Cu}-4 \mathrm{wt} . \% \mathrm{CNT}$ composite. The distance between the anode and sample equals to $0.25 \mathrm{~mm}$.

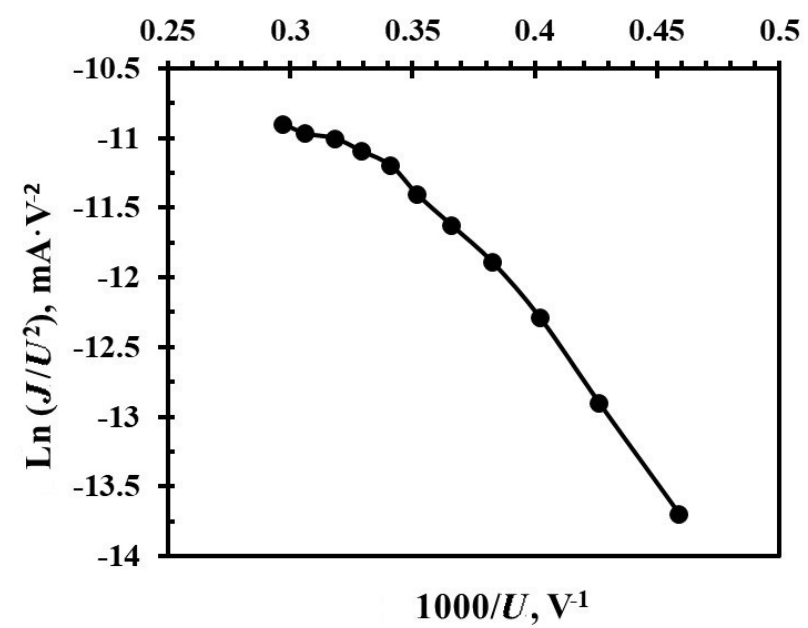

Fig. 5. Current-voltage diagram of the field electron emission from Cu-4 wt.\%CNT composite in Fowler-Nordheim coordinates.

The dependence of the emission current on the voltage plotted in Fowler-Nordheim coordinates is linear in the interval $1000 / U=(0.45-0.34) \mathrm{V}^{-1}$, while at $1000 / U=(0.34-0.3) \mathrm{V}^{-1}$ the increase of $J$ with $U$ slows down. This can be explained by the breakdown of the tips of CNT clusters due to the resistive heating.

Acknowledgments. The authors acknowledge the support from the Presidium of the Russian Academy of Sciences under the Basic Research Program I.7 "New developments in promising areas of energetics, mechanics and robotics". The microstructure studies of the copper matric CNT composite were carried out according to the State task of IMSP RAS \#AAAA-A17-117041310213-0. Electron microscopic studies were carried out using the facilities of shared services center of IMSP RAS "Structural and Physical-Mechanical Studies of Materials".

\section{References}

1. S. Iijima. Nature. 354, 56 (1991). Crossref

2. E.W. Wong, P.E. Sheehan, C. M. Lieber. Science. 277, 1971 (1997). $\underline{\text { Crossref }}$

3. J.-P. Salvetat, G. A.D. Briggs, J.-M. Bonard, R. R. Bacsa, A. J. Kulik, T. Stockli, N. A. Burnham, L. Forro. Physical Review Letters. 82, 944 (1999). $\underline{\text { Crossref }}$ 
4. A. Agarwal, S.R. Bakshi, D. Lahiri. Carbon nanotubes reinforced metal matrix composites. Boca Raton, CRC Press (2018). 325 p. Crossref

5. S. Suárez, E. Ramos-Moore, B. Lechthaler, F. Mücklich. Carbon. 70, 173 (2014). Crossref

6. V.T. Pham, H.T. Bui, B.T. Tran, V.T. Nguyen, D. Q. Le, $\mathrm{X}$. T. Than et al. Advances in Natural Sciences: Nanoscience and Nanotechnology. 2, 015006 (2011). Crossref

7. A. K. Shukla, N. Nayan, S. V.S. N. Murty, S.C. Sharma, P. Chandran, S. R. Bakshi, K. M. George. Materials Science and Engineering A. 560, 365 (2013). Crossref

8. M. Jafari, M.H. Abbasi, M.H. Enayati, F. Karimzadeh. Advanced Powder Technology. 23, 205 (2012). Crossref

9. A. Kasperski, A. Weibel, C. Estournès, Ch. Laurent, A. Peigney. Carbon. 53, 62 (2013). Crossref

10. Ch. Guiderdoni, C. Estournès, A. Peigney, A. Weibel, V. Turq, Ch. Laurent. Carbon. 49, 4535 (2011). Crossref

11. P.V. Trinh, N.V. Luan, D.D. Phuong, P.N. Minh, A. Weibel, D. Mesguich, C. Laurent. Composites: Part A. 105, 126 (2018). Crossref

12. M. R. Akbarpour, S. Alipour, M. Farvizi, H.S. Kim. Achieve of Civil and Mechanical Engineering. 19, 694 (2019). Crossref

13. R. Murugesan, M. Gopal, G. Murali. Applied Surface Science. 495, 143542 (2019). Crossref

14. B. Duan, Y. Zhou, D. Wang, Y. Zhao. Journal of Alloys and Compounds. 771, 498 (2019). Crossref

15. T. Tokunaga, K. Kaneko, Z. Horita. Materials Science and Engineering A. 490, 300 (2008). Crossref

16. S-H. Joo, S.C. Yoon, C.S. Lee, D.H. Nam, S. H. Hong, H.S. Kim. Journal of Materials Science. 45, 4652 (2010). $\underline{\text { Crossref }}$

17. R. K. Khisamov, K. S. Nazarov, L. R. Zubairov et al. Physics of the Solid State. 57, 1206 (2015). $\underline{\text { Crossref }}$
18. R. K. Khisamov, K. S. Nazarov, S. N. Sergeev, R. R. Kabirov, R.R. Mulyukov, A.A. Nazarov. Letters on Materials. 5, 119 (2015). (in Russian) Crossref

19. D.D. Phuong, P.V. Trinh, N.V. An, N.V. Luan, P.N. Minh, R. Kh. Khisamov, K.S. Nazarov, L.R. Zubairov, R.R. Mulyukov, A.A. Nazarov. Journal of Alloys and Compounds. 613, 68 (2014). Crossref

20. S. Arai, T. Saito, M. Endo. Electrochemical and SolidState Letters. 11, D72 (2008). Crossref

21. C. B. Mo, J. W. Hwang, S. I. Cha, S. H. Hong. Carbon. 47, 1276 (2009). Crossref

22. M. Deng, G. Ding, Y. Wang, H. Wu, Y. Yao, L.Zhu. Carbon. 47, 3466 (2009). Crossref

23. M. Markushev, E. Avtokratova, O. Sitdikov. Letters on Materials. 7, 459 (2017). $\underline{\text { Crossref }}$

24. R.Kh. Khisamov, K.S. Nazarov, A.V. Irzhak, R. U. Shayakhmetov, I.I. Musabirov, R.R. Timirayev, Y.M. Yumaguzin, R. R. Mulyukov. Letters on Materials. 9, 212 (2019). Crossref

25. V.N. Danilenko, S.N. Sergeev, J.A. Baimova, G.F. Korznikova, K.S. Nazarov, R. K. Khisamov, A. M. Glezer, R. R. Mulyukov. Materials Letters. 236, 51 (2019). Crossref

26. A.I. Benedik, T.M. Krachkovskaya, V.I. Shesterkin. Technical Physics. 60, 1535 (2015). Crossref

27. R.H. Fowler, L. Nordheim. Proceedings of the 8 Royal Society of London. 119, 173 (1928). Crossref

28. A. V. Eletskii. Physics-Uspekhi. 45, 369 (2002). Crossref

29. Y. Song, J. Li, Q. Wu, C. Yi, H. Wu, Z. Chen, W. OuYang. Journal of Alloys and Compounds. In Press (2019). Crossref

30. P. Vincent, S.T. Purcell, C. Journet, V.T. Binh. Physical Review B. 66, 075406 (2002). Crossref 